\title{
System Identification And Controller Design For An Integrating Process With Time Delay
}

\author{
Soundarya M S, \\ Department of EIE School of EEE SASTRA UNIVERSITY Thanjavur, India, 613401 soundaryaseenu@gmail.com \\ Jenitha Rashmi P \\ Department of EIE School of EEE SASTRA UNIVERSITY Thanjavur, India, 613401 jenitharashmi@gmail.com
}

Akilaa Sre R

Department of EEE School of EEE SASTRA UNIVERSITY Thanjavur, India, 613401 akilaasre@ gmail.com

Uma $S$

Assistant Professor, Dept. of EIE School of EEE SASTRA UNIVERSITY Thanjavur, India, 613401 umasrinivasan@eie.sastra.edu

\begin{abstract}
System identification has been carried out in real time for a laboratory scale integrating tank system. IMC PID, PI controller using Direct Synthesis method, PI lead-lag controller designed by DS method are implemented in real time. Extensive simulation studies are also carried out for the integrating process with intelligent fuzzy, self tuned fuzzy PI controllers. The controllers give good disturbance rejection response and significant improved set point tracking.
\end{abstract}

Keywords: Integrating process, IMC PID, PI and PI with lead lag, fuzzy, self tuned fuzzy PID

\section{Introduction}

Unlike gravity drained tanks where the exit flow rate increases and decreases as tank level rises and falls, the discharge flow rate in non self regulating example is strictly regulated by a pump. As a consequence, the physics do not naturally work to balance the system when any of the stream flow rates change. This lack of a natural balancing behavior is why the pumped tank is classified as an integrating process which is an example for unstable systems.

Time delays are commonly encountered in industrial processes. In the open literature of integrating processes with time delay, simple PID controllers in simple feedback loop has been addressed by many researchers (Kwak et al. (1), Sree and Chidambaram (2), Wang and Cai (3), Skogested (4), Lee et al.(5). For clear illustration, the paper is organized as follows. Process description is explained in section 2, followed by the system identification in section 3 , Section 4 discusses the design of various controllers, section 5 the simulation results, section 6 the experimental results and finally conclusions given in section 7 .

\section{Process Description}

A laboratory scale pumped tank system has been designed and the schematic diagram of the process is shown in Figure 1 respectively. By pumping out water from the cylindrical tank at a constant rate with a pump the process is developed as an integrating process. In Figure 1, pump1 provides the process input to the process tank and pump2 provides the disturbance input to the process tank. Level has been considered as the Process variable (PV). Out flow from the tank has been considered as the manipulated variable (MV). This approximates the behavior of a centrifugal pump operating at relatively low throughput. An air-to-close control valve is connected in the output so as to manipulate the out flow. A bypass connection with a non-returnable (NR) valve is provided between pump 3 and the control valve to avoid the reverse pressure to the output pump. Rotameters are connected in both the input and output side for manual read out of the flow rate.

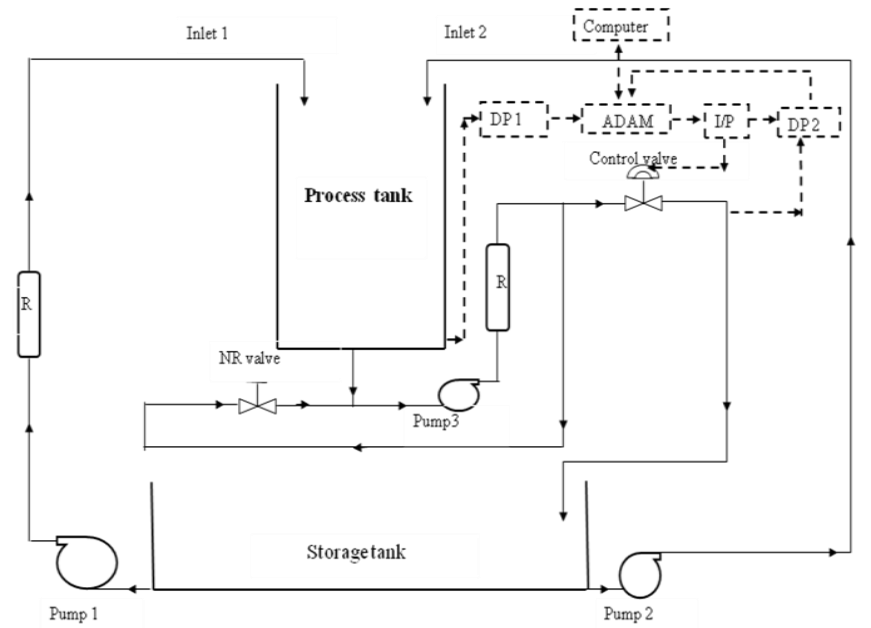

Fig.1. Schematic diagram of the Integrating process

Differential pressure (DP) transducer (DP1) has been used as the level sensor. One end of the DP is connected to the bottom of the tank and as the tank is open, the other end is left open 
for atmospheric pressure. The differential pressure transducer is calibrated in terms of $\mathrm{mA}$ which is an indication of the level (PV) in the tank. An orifice plate is connected in the outflow pipe of the tank and the ends of the orifice are connected to another differential pressure transducer (DP2) which has been used for out flow inference. DP2 is calibrated in terms of $\mathrm{mA}$ which is a measure of the outflow (MV). Hence DP1 is a level sensor and DP2 is a flow sensor. Outputs of the transducers (DP1 and DP2) are given to the analog input channel of ADAM 5000 module, which in turn is connected with the PC through the RS serial 232 port. The controller implementations are carried out using MATLAB programs. Based on the controller output, the ADAM module gives an equivalent analog current output of 4-20 mA which is a measure of the controller output. To the output channel of ADAM MODULE a current to pressure (I to P) converter has been connected. The $4-20 \mathrm{~mA}$ analog current output of ADAM module is given as the input to $\mathrm{I} / \mathrm{P}$ (current to pressure) converter. The convertor gives an equivalent output of 3-15 psi which in turn actuates the final control element (Air to close control valve) so as to execute the control action. The photographic view of the setup is shown in Figure 2. Table 1 shows the specification details.

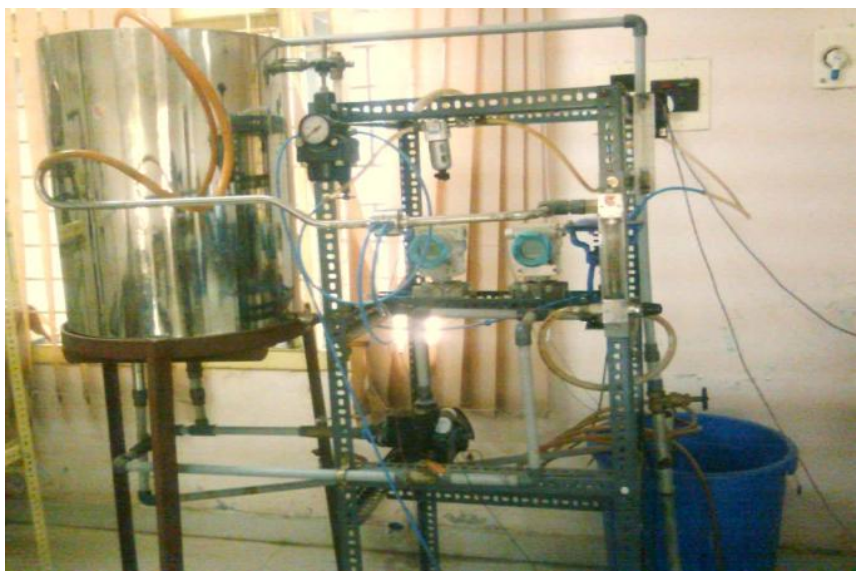

Fig. 2 Photographic view of the integrating tank experimental setup.

Table 1 Specification Chart

\begin{tabular}{|l|l|}
\hline Specification & Details \\
\hline STORAGE TANK & 120 LITERS \\
\hline PROCESS TANK & 100 LITERS \\
\hline LEVEL DPT & SIEMENS (O/P in mA) \\
\hline FLOW DPT & SIEMENS (o/p in $\mathrm{mA})$ \\
\hline Rotameters & $0-10$ LPM, 0-5 LPM \\
\hline I/P convertor & I/P 4- 20 $\mathrm{mA}$ and O/P 3 - 15 PSI \\
\hline
\end{tabular}

\section{System Identification}

System identification has been carried out for the integrating process. Graphical model-fitting technique has been adapted for identification of the integrating process. An important difference between the graphical technique for self-regulating processes and non self-regulating processes is that the non self-regulating processes need not start at a steady value (steady-state) before a step change is applied in the manipulated variable. The graphical method proposed by Arbogasat et al. (6) has been used to model the integrating process as a first order plus dead time integrating (FOPDT integrating) model as given below

$$
\frac{Y(s)}{U(s)}=\frac{k_{p} e^{-\theta p s}}{s}
$$

Using the graphical method the process gain $\mathrm{k}_{\mathrm{p}}$ and the process time delay $\theta_{\mathrm{p}}$ are obtained.

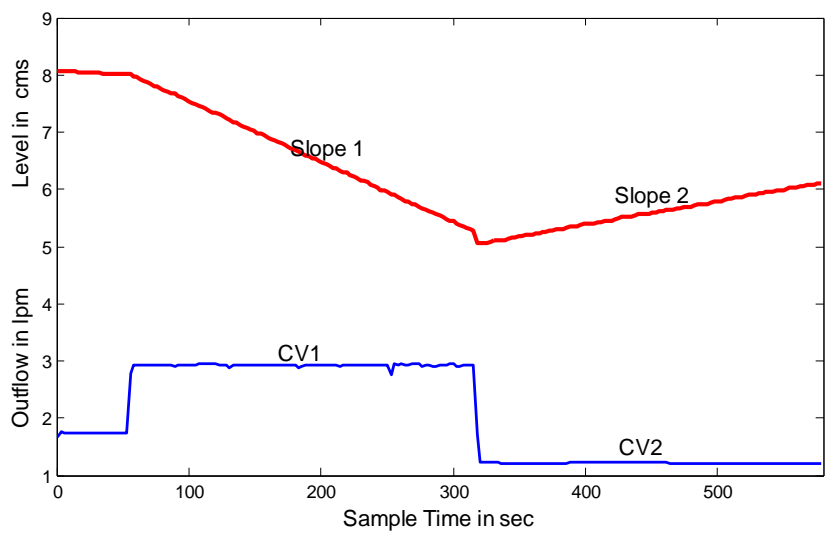

Fig. 3 Open loop response of the integrating system

The graphical method of fitting a FOPDT integrating model to process data requires a data set that includes at least two constant values of manipulated variable $\left(\mathrm{CV}_{1}, \mathrm{CV}_{2}\right)$ and both must be held constant long enough such that the slope of the measured process variable (PV) response may be visually identified in the data. There must be enough difference between $\mathrm{CV}_{1}$ and $\mathrm{CV}_{2}$ such that each produces a distinguishably different slope in the PV response. In practice, often it is difficult to obtain steady state data from non-self regulating process, however this method is advantageous.

Real time experimental work has been carried out in the integrating tank setup. Initially the process has been allowed to run for a run time of $50 \mathrm{sec}$ with an inflow of 3 LPM and an outflow of 3 LPM. After reaching the steady state, a positive pulse input of 4 LPM is maintained in the manipulated variable for a period of $300 \mathrm{sec}$ causing liquid level (PV) to fall. Thus a negative slope (Slope 1) in the process variable has been obtained. For a negative pulse input of 2 LPM in the manipulated variable is maintained for a period of $300 \mathrm{sec}$ causing an upward slope in the liquid level. Thus a positive slope (Slope 2) has been obtained in the process variable. The graphical technique discussed is concerned with the slopes (rates of change) in the PV and the controller output signal that caused each PV slope. Thus both the positive and negative slopes are obtained. The corresponding identification response is shown in Figure 3 respectively.

The FOPDT integrating model as stated in eq. 1 
slope $_{1}=\left.\frac{d y(t)}{d t}\right|_{1}$

slope $_{2}=\left.\frac{d y(t)}{d t}\right|_{2}$

$k_{p}=\frac{\text { slope }_{2}-\text { slope }_{1}}{u_{2}-u_{1}}$

The dead time is approximated as the difference in time between the step change in manipulated variable and the beginning of the PV response.

Substituting the data in equations $2-4$, the process gain is obtained as

$$
\begin{aligned}
& \text { slope }_{1}=\left.\frac{d y(t)}{d t}\right|_{1}=\frac{\Delta P V_{1}}{\Delta t_{1}}=\frac{7.1-6.59}{(55-73)} \\
& \text { slope }_{2}=\left.\frac{d y(t)}{d t}\right|_{2}=\frac{\Delta P V_{2}}{\Delta t_{2}}=\frac{5.41-5.61}{(157-181)} \\
& k_{p}=\frac{\text { slope }_{2}-\text { slope }_{1}}{C V_{2}-C V_{1}}=\frac{0.00833-(-0.0283)}{2-4} \mathrm{~cm} / \mathrm{sec}
\end{aligned}
$$

A measurement delay of 2 seconds is introduced and hence $\theta_{\mathrm{p}}$ is considered as 2. Thus the FOPDT integrating model is obtained as

$$
\frac{Y(s)}{U(s)}=\frac{k_{p} e^{-\theta p s}}{s}=\frac{-0.018315}{s} e^{-2 s}
$$

\section{Controllers Design}

The simple feedback block diagram showing the process and the controller is shown in Fig. 4, where $G_{p}$ is the transfer function of the process and $G_{c}$ is the transfer function of the controller.

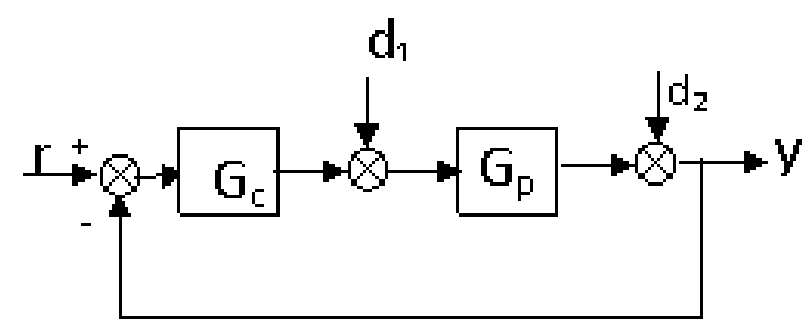

Fig. 4 Feedback control structure

The designed controllers are implemented in real time in simple closed loop structure as shown in figure 4, and are elaborated in case (i),(ii) and in (iii). Extensive simulation studies are carried out for the controllers discussed in case (iv)\&(v)

\section{Case (i) IMC method}

PID controller is the most commonly used controller in industry. The PID controller form is considered in the ideal form as given below

$u(t)=k_{c}\left(e(t)+\frac{1}{\tau_{i}} \int e(t) d t+\tau_{d} \frac{d e(t)}{d t}\right)$

Internal model control (IMC) technique is adopted to design a conventional PID controller for the developed FOPDT integrating model. Table 2 shows IMC PID tuning correlations. Bequette (11)

Table 2 IMC tuning correlations for FOPDT integrating processes

\begin{tabular}{|l|c|c|c|}
\hline & Controller gain $\mathrm{k}_{\mathrm{c}}$ Integral time $\tau_{\mathrm{i}}$ & Derivative time $\tau_{\mathrm{d}}$ \\
\hline IMC PID & $\frac{1}{k_{p}} \frac{2}{\left(\lambda+\theta_{p} / 2\right)}$ & $2 \lambda+\theta_{p}$ & $\frac{\theta_{p} \lambda+\theta_{p}^{2} / 4}{2 \lambda+\theta_{p}}$ \\
\hline
\end{tabular}

\section{Case (ii) PI lead-lag Controller}

The PI lead-lag disturbance rejection controller designed by Uma et al (8) is adapted in simple feedback loop for practical implementation. The main advantage of the lead compensator is that it increases the resonant frequency, which results in increasing the upper bound of frequency in the low frequency region and thus provides improved closed loop performances. The PI lead-lag controller is considered as given below

$G_{c d}=\left(k_{c d}+\frac{k_{i d}}{s}\right) \frac{\left(\alpha_{d} s+1\right)}{\left(\beta_{d} s+1\right)}$

The characteristic equation containing the $\mathrm{G}_{\mathrm{cd}}$ term is $1+G_{c d} G_{m} e^{-\theta_{m} s}=0$. Substituting the expressions for $\mathrm{G}_{\mathrm{cd}}$ and $\mathrm{G}_{\mathrm{m}}$ from eqs. (10 \& 1) and using a first order Pade approximation for time delay results in

$$
1+\frac{k_{m}}{s}\left(\left[k_{c d}+\frac{k_{i d}}{s}\right] \frac{\left(\alpha_{d} s+1\right)}{\left(\beta_{d} s+1\right)}\right)\left(\frac{1-0.5 \theta_{m} s}{1+0.5 \theta_{m} s}\right)=0
$$

Considering $\alpha_{d}=0.5 \theta_{m}$, after simplification, eq. (11) reduces to

$$
d_{3} s^{3}+d_{2} s^{2}+d_{1} s+1=0
$$

where

$$
\begin{aligned}
& d_{3}=\left(\beta_{d}\right) /\left(k_{m} k_{i d}\right) \\
& d_{2}=\left(1-0.5 \theta_{m} k_{m} k_{c d}\right) /\left(k_{m} k_{i d}\right)
\end{aligned}
$$


$d_{1}=\left(k_{m} k_{c d}-0.5 \theta_{m} k_{m} k_{i d}\right) /\left(k_{m} k_{i d}\right)$

According to direct synthesis method, the characteristic equation (eq. 12) is considered to follow the desired trajectory in the form of

$$
\left(\lambda_{d} s+1\right)^{3}=0
$$

Expanding Eq. 13 and equating the corresponding coefficients of $\mathrm{s}$ in Eq. 13 and Eq. 12, the controller parameters $k_{c d}, k_{i d}, k_{d d} \alpha_{d}$ and $\beta_{d}$ are obtained as

$$
k_{c d}=\frac{1-3 \lambda_{d}^{2} k_{m} k_{i d}}{k_{m}\left(0.5 \theta_{m}\right)}
$$

$$
k_{i d}=\frac{1}{k_{m}\left(1.5 \theta_{m} \lambda_{d}+0.2 \theta_{m}^{2}+3 \lambda_{d}^{2}\right)}
$$

$\alpha_{d}=0.5 \theta_{m}$ and $\beta_{d}=\lambda_{d}^{3} k_{m} k_{i d}$

Here $\lambda_{\mathrm{d}}$ is the tuning parameter. The tuning parameter has to be selected to obtain good nominal and robust control performances. To obtain the phase lead, ' $\alpha_{d}$ ' should be always greater than ' $\beta_{d}$ '. The value of $\beta$ is considered as $0.1 \beta_{d}$. Rao and Chidambaram (9). With the tuning parameter $\lambda=10$ and with a set point filter of $0.9[10]$, the PI lead-lag controller parameters are obtained as $k_{c d}=-5.1136, k_{i d}=-0.1650, \alpha_{d}=1$ and $\beta_{d}=3.0211$. The value of $\beta_{d}$ is considered as 0.1 times the value obtained as 0.30211 .

With set point weighting, the PID controller in Eq. (10) should be implemented in the form of

$$
u(t)=k_{c}\left[\left(\varepsilon y_{r}-y\right)+\left(\frac{1}{\tau_{i}}\right) \int e d t+\tau_{d} \frac{d e}{d t}\right]
$$

where $\mathrm{e}=\mathrm{y}_{\mathrm{r}}-\mathrm{y}$ in which $\varepsilon$ is the set point weighting parameter which should be selected in such a way that the closed loop response is smooth without much overshoot and settling time. The range for $\varepsilon$ is $0 \leq \varepsilon \leq 1$. Higher values of $\varepsilon$ (near to the value of one) exhibits large overshoot in the set point response and lesser values of $\varepsilon$ shows slow response behavior. Chidambaram (10)

\section{Case (iii) PI Controller}

A simple PI controller proposed by Rao et al (7) for set point tracking has been experimented for which the controller equations are given below.

$k_{c}=2 / \mathrm{k}_{\mathrm{p}} \lambda$

$k_{i}=k_{c} / \tau_{\mathrm{i}}$

where $\tau_{\mathrm{i}}=2 \lambda$

\section{Case (iv) Intelligent fuzzy controller}

The basic block diagram of a fuzzy controller is given in Figure5. For the fuzzy controller the error and rate of error are considered as inputs and the output as controller output. The fuzzy inputs and the output are divided into 5 membership functions as Negative Big (BN), Negative (N), Zero (Z), Positive (P) and Positive Big (BP) and with these 25 rules are framed. The membership function considered is a triangular membership function. The rules framed for the Fuzzy Inference System (FIS) is given in table 3.

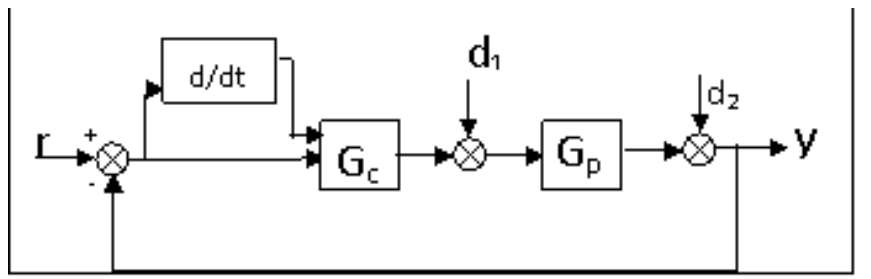

Fig. 5. Basic block diagram of fuzzy controller

Table 3. Rule base table for FIS

\begin{tabular}{|l|c|c|c|c|c|}
\hline Error $\backslash$ Rate of Error & BN & N & Z & P & BP \\
\hline BN & BN & BN & BN & N & Z \\
\hline N & BN & BN & BN & Z & P \\
\hline Z & BN & N & Z & P & BP \\
\hline P & N & Z & P & BP & BP \\
\hline BP & Z & P & BP & BP & BP \\
\hline
\end{tabular}

Case (v) Self tuned Fuzzy PID

Self tuned fuzzy PID is a technique in which the PID values are obtained from fuzzy controller. Soundarya et al. (13). For the output fuzzy sets the scaling of range has been done corresponding to the formulas given below Zuraida Muhammad (12).

$$
\begin{aligned}
& k_{c}^{\prime}=\frac{k_{c}-k_{c, \text { min }}}{k_{c, \text { max }}-k_{c, \text { min }}} \\
& k_{i}^{\prime}=\frac{k_{i}-k_{i, \text { min }}}{k_{i, \text { max }}-k_{i, \text { min }}} \\
& k_{d}^{\prime}=\frac{k_{d}-k_{d, \text { min }}}{k_{d, \text { max }}-k_{d, \text { min }}}
\end{aligned}
$$

\section{Simulation results}

Simulation has been carried out with a unit step input applied at time $\mathrm{t}=0 \mathrm{sec}$ and the corresponding closed loop responses obtained are shown in figure 6. An output disturbance of magnitude 0.1 has been provided at time $\mathrm{t}=110 \mathrm{sec}$ and the corresponding closed loop responses are shown in figure 7. From the figure it is clear that fuzzy controller gives improved set point tracking response.

In order to check the robustness of the controller, perturbations are considered in the process parameter, a 
perturbation of $+20 \%$ has been considered in the process gain parameter in the process time delay parameter and the corresponding closed loop responses are shown in figure 8 respectively.

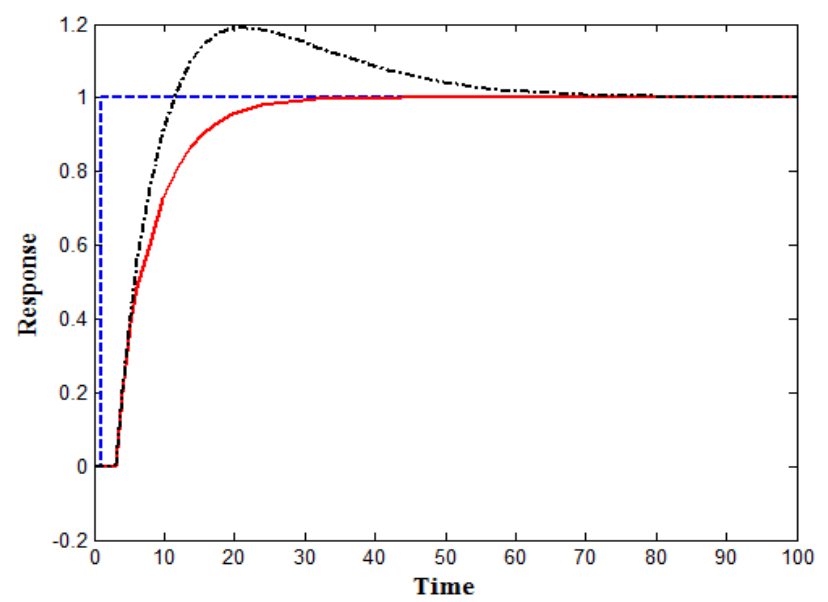

Fig. 6 Closed loop responses of IMC PID (dash-dot), fuzzy Controller(Solid) and applied input(dash)

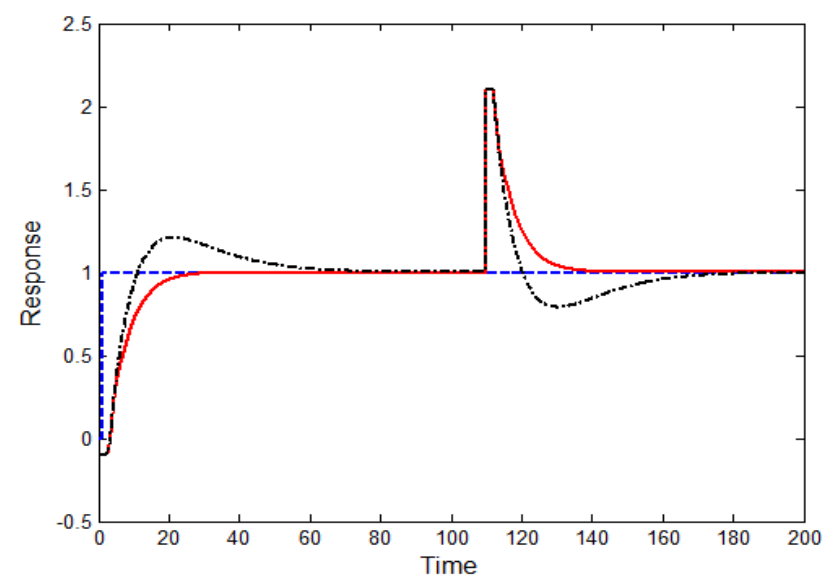

Fig. 7 Closed loop responses of IMC PID (dash-dot), fuzzy Controller(Solid) and applied input(dash) for perfect conditions

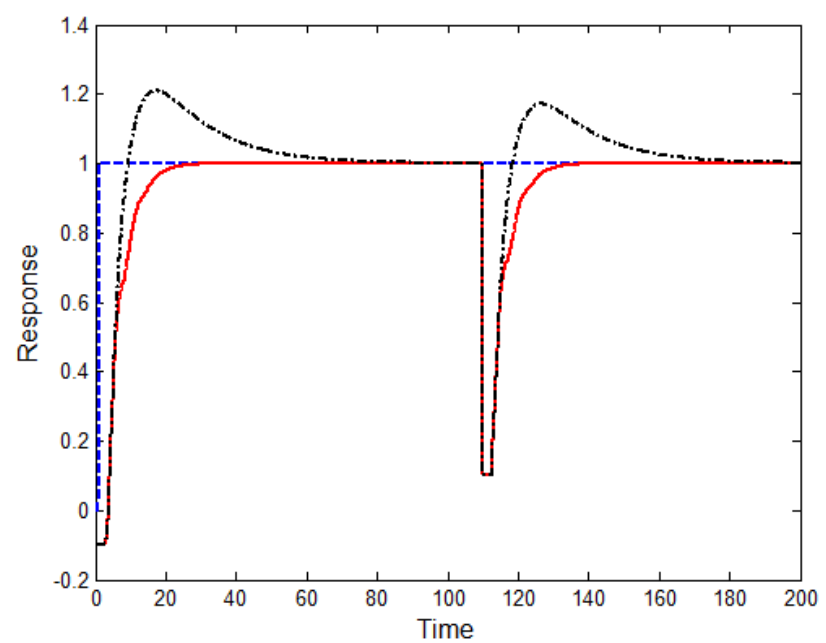

Fig. 8 Closed loop responses of IMC PID (dash-dot), fuzzy Controller (Solid) for perturbed condition, for a perturbation of $+20 \%$ in $k_{p}$ and $\theta_{p}$
In this study, the variable range of the parameters $\mathrm{K}_{\mathrm{c}}, \mathrm{K}_{\mathrm{i}}$ and $\mathrm{K}_{\mathrm{d}}$ varies in between $\left[\mathrm{k}_{\mathrm{c}, \min }, k_{c, \max }\right],\left[k_{i \min }, k_{i, \max }\right],\left[k_{d, \min }, k_{d, \max }\right]$ (Zuraida Muhammad (12)). The range of PID parameters are obtained from the simulation of PID controller to get the feasible and optimum performance from which the range for each parameters are $\mathrm{k}_{\mathrm{c}}=\left[\begin{array}{l}9.9273 \\ 21.7636\end{array}\right], \mathrm{k}_{\mathrm{i}}=[2.3496$ $4.6986]$ and $\mathrm{k}_{\mathrm{d}}=\left[\begin{array}{ll}0.0671 & 1.9253\end{array}\right]$ respectively. With these values and with equation 16 the appropriate value of $\mathrm{k}_{\mathrm{c}}, \mathrm{k}_{\mathrm{i}}$ and $\mathrm{k}_{\mathrm{d}}$ are obtained as $k_{c}=11.182 k_{c}^{\prime}+9.9273$ $k_{i}=2.3493 k_{i}^{\prime}+2.3493$ and $k_{d}=1.8582 k_{d}^{\prime}+0.0671$

With these values for a unit step input provided at time $t=0$ $\mathrm{sec}$ and a disturbance of magnitude 0.1 at time $t=70 \mathrm{sec}$ has been provided and the corresponding closed loop response obtained is shown in figure 9. The closed loop responses obtained are for perfect conditions with no mismatch between the plant parameters and the model parameters. From the response it is clear that self tuned fuzzy PID gives a good set point tracking with no overshoot and also a good disturbance rejection.

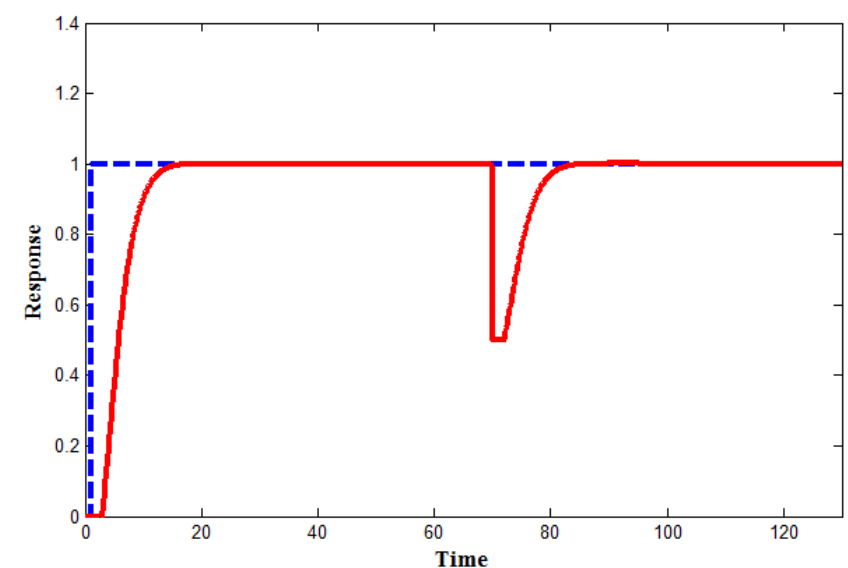

Fig. 9 Closed loop responses of Self tuned fuzzy PID (Solid) and applied input (dash) for perfect conditions

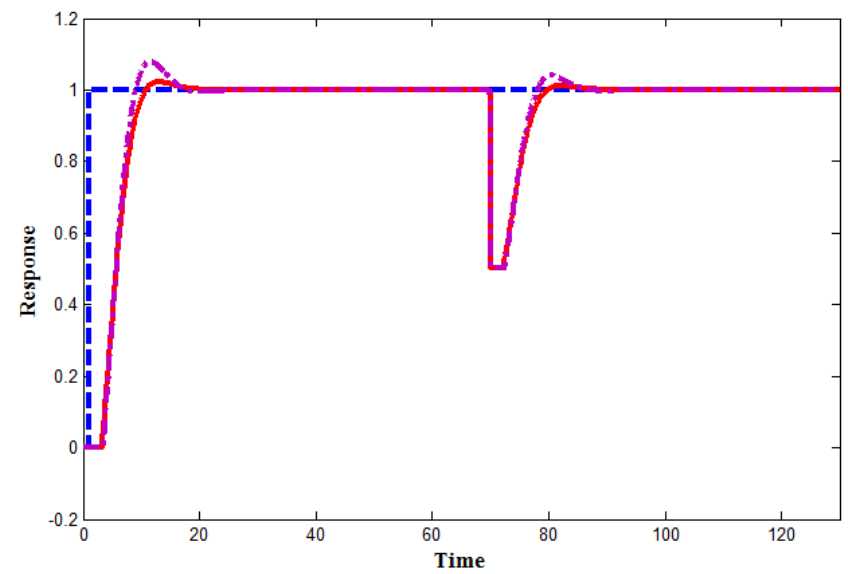

Fig. 10 Closed loop responses of Self tuned fuzzy PID (Solid) for perturbed condition, for a perturbation of $+\mathbf{1 0 \%}$ in $k_{p}$ and $\theta_{p}$ (Solid) and for $+\mathbf{2 0 \%}$ perturbation in $k_{p}$ and $\theta_{p}$ (dash-dot) 
In order to show the robustness of the designed controller, perturbations are considered in the process parameters as $+10 \%$ in both process gain and in the time delay parameter and $+20 \%$ in both process gain and in the time delay parameter respectively. The obtained closed loop responses are shown in figure 10. From the responses shown it is clear even for perturbed conditions also the designed controller shows good set point tracking and disturbance rejection performance.

\section{Experimental Results}

Experimentation has been carried out with IMC PID, PI controller and with PI Lead-lag controller.

\section{IMC PID Implementation:}

With IMC PID, with the tuning parameter $\lambda=10$ and the set point weighting as 0.9 , the PID parameters are $\mathrm{k}_{\mathrm{c}}=-9.9273, \tau_{\mathrm{i}}$ $=22$ and $\tau_{\mathrm{d}}=0.9545$. The real time closed loop response and the corresponding manipulated action obtained is shown in Figure 11 respectively.

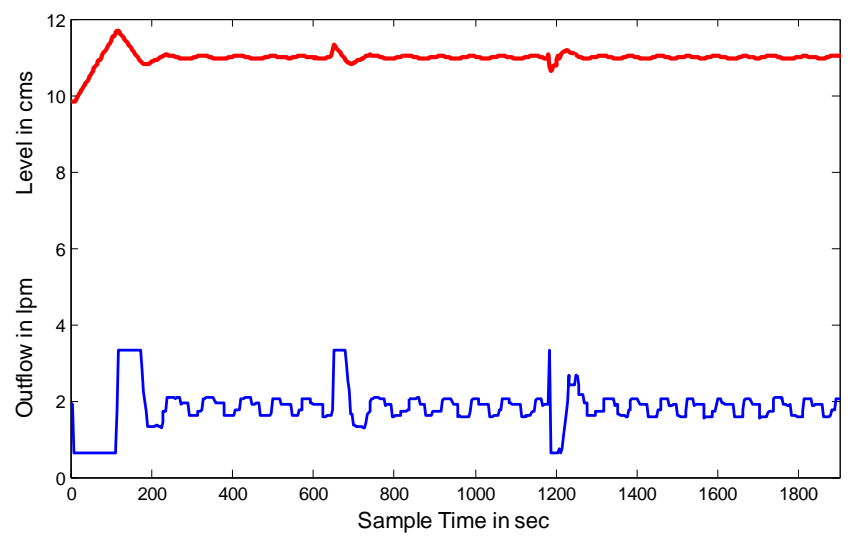

Fig. 11 Closed loop response and the control valve action with the PID controller

\section{PI lead-lag controller Implementation}

With the tuning parameter $\lambda=10$ and with a set point filter of $0.9[10]$, the PI lead-lag controller parameters are obtained as $k_{c d}=-5.1136, k_{i d}=-0.1650, \alpha_{d}=1$ and $\beta_{d}=3.0211$. The value of $\beta_{d}$ is considered as 0.1 times the value obtained as 0.30211 .

With these controller parameters, the PI lead-lag controller is implemented for on-line control of level of the integrating process. The real time closed loop response and the corresponding control valve action obtained are shown in Figure 12.

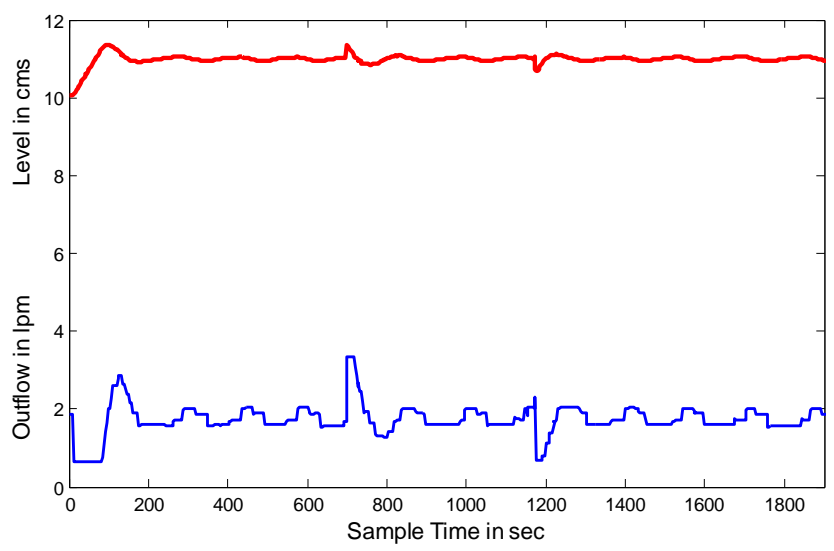

Fig. 12 Closed loop response and the control valve action with the PI lead-lag controller

Table 4. IAE \& ISE performance specifications

\begin{tabular}{|c|c|c|c|}
\hline & $I A E$ & $I S E$ & \\
\hline Fuzzy & 7.1567 & 4.4887 & \multirow[t]{2}{*}{ For perfect conditions } \\
\hline$I M C P I D$ & 10.4189 & 4.6195 & \\
\hline Fuzzy & 6.3143 & 4.2571 & \multirow{2}{*}{$\begin{array}{l}\text { For a perturbation of } \\
20 \% \text { in } k_{p} \text { and } \theta_{p}\end{array}$} \\
\hline$I M C P I D$ & 9.6113 & 4.5100 & \\
\hline \multirow{2}{*}{$\begin{array}{l}\text { Self tuned } \\
\text { fuzzy } P I D\end{array}$} & 8.0933 & 4.9618 & For perfect conditions \\
\hline & 7.8959 & 4.9793 & $\begin{array}{l}\text { For a perturbation of } \\
20 \% \text { in } k_{p} \text { and } \theta_{p}\end{array}$ \\
\hline
\end{tabular}

\section{Conclusion}

IMC PID controller, PI controller and a PI lead-lag controller are experimentally implemented for on-line level control in real time. Though IMC PID shows large overshoot the other two controllers, both simple PI and PI lead-lag controller shows less overshoot in set point tracking as well a good disturbance rejection performance with smooth valve action. Thus real time results of the designed controller's exhibit good set point tracking and a good disturbance rejection. The same has been verified with simulation studies and robustness check also has been carried out.

\section{References}

1. H.J.Kwak, S.W.Sung, I.B.Lee. On-line process identification and auto tuning for integrating processes. Ind. Eng. Chem. Res. 36(12), 1997, 532938.

2. M. Chidambaram, R.P. Sree, A simple method of tuning PID controllers for integrating/dead-time processes, Comp. \& Chem. Engg. 27, 2003, 211-15.

3. Y.G.Wang, W.J.Cai, Advanced PID tuning for integrating and unstable processes with gain and phase margin specifications, Ind. Eng. Chem. Res. 41, 2002, 2910-14.

4. S.Skogested, Simple analytical rules for model reduction and PID controller tuning, Journal of Process Control, 13, 2003, 291-309. 
5. Y.Lee, J.Lee, S.Park, PID controllers tuning for integrating and unstable processes with time delay. Chem. Eng. Sci. 55, 2000, 3481-93.

6. Arbogasat, J. E., Cooper, D. J., and Rice, R. C. Graphical technique for modeling integrating (Nonself Regulating) processes without steady state process data, 2007, 194, 12, $1566-78$

7. A.Seshagiri Rao, V.S.R.Rao and M.Chidambaram, Set point weighted modified Smith predictor for integrating and double integrating processes with time delay, ISA Transactions, 46, 2007, 59-71.

8. S. Uma, M. Chidambaram and A. Seshagiri Rao, Setpoint weighted modified Smith predictor with PID filter controllers for non-minimum-Phase (NMP) integrating processes, Chemical Engineering Research \& Design, 2010, 88, 5-6, 592-601.

9. Rao, A. S. and Chidambaram, M. Enhanced two degrees of freedom control for second order unstable processes with time delay. Ind. Eng. Chem. Res. 2006, 45, 3604-14.

10. Chidambaram, M. Set point weighted PI/PID controllers for integrating plus dead time processes. Proceedings of the national symposium on intelligent measurement \& control, 2000, 324-28.

11. Bequette, B. W. Process Control: modeling, design \& simulation, Prentice Hall of India Pvt. Ltd., New Delhi, 2000.

12. Zuraida Muhammad, Zakiah Mohd Yusoff, Nurhani Kasuan, Mohd Noor Nasriq Nordin, Mohd Hezri Fazalul Rahiman, Mohd Nasir Taib, Online Tuning PID using Fuzzy Logic Controller with Self-Tuning Method, IEEE 3rd International Conference on System Engineering and Technology, 19 - 20 Aug. 2013, Shah Alam, Malaysia.

13. Soundarya M.S., Jenitha Rashmi, AkilaaSre R, Uma.S Cart Position Control of Linear Inverted Pendulum (LIP) using Intelligent techniques, International Journal of Applied Engineering research, 10, 15, 2015, 35805-35809. 